A N N A L E S Annales de Bretagne et des Pays de l'Ouest

\title{
La première Compagnie des Indes. Apprentissages, échecs et héritage 1664-1704
}

\section{Pierrick Pourchasse}

\section{(2) OpenEdition}

9 Journals

Édition électronique

URL : https://journals.openedition.org/abpo/4240

DOI : $10.4000 / a b p o .4240$

ISBN : 978-2-7535-7720-6

ISSN : 2108-6443

Éditeur

Presses universitaires de Rennes

Édition imprimée

Date de publication : 18 décembre 2018

Pagination : 182-183

ISBN : 978-2-7535-7718-3

ISSN : 0399-0826

\section{Référence électronique}

Pierrick Pourchasse, «La première Compagnie des Indes. Apprentissages, échecs et héritage 1664-1704 ", Annales de Bretagne et des Pays de l'Ouest [En ligne], 125-4 | 2018, mis en ligne le 18 décembre 2018, consulté le 02 mars 2022. URL : http://journals.openedition.org/abpo/4240 ; DOI : https://doi.org/ $10.4000 / a b p o .4240$ 
historique. On peut regretter cependant l'absence de plans parcellaires (le plan Robelin de 1721) qui apporteraient un éclairage supplémentaire à l'analyse stylistique. La façade, comme le fait justement remarquer Françoise Boudon, est la manifestation verticale de la parcelle, qui soutient toute réalité architecturale. Cet ouvrage qui donne au lecteur les clés de compréhension de l'évolution urbaine est finalement un jalon, alertant sur la nécessité de multiplier les datations dendrochronologiques, qui couplées à l'analyse stylistique viendront renouveler considérablement notre connaissance du patrimoine en pan-de-bois.

Matthieu LE BouLCH

MÉNARD-JACOB, Marie, La première Compagnie des Indes. Apprentissages, échecs et héritage 1664-1704, Rennes, PUR, coll. " Histoire », 2016, 316 p., préface de Gérard Le Bouëdec.

Le travail de Marie Ménard-Jacob, porte sur la première Compagnie des Indes (1664-1704) dont l'histoire a été totalement éclipsée par celle la grande Compagnie des Indes du XVIII ${ }^{\mathrm{e}}$ siècle (1723-1769). L'entreprise a cependant joué un rôle fondamental en posant les bases de la présence française dans l'espace asiatique. Pour aborder cette première aventure commerciale vers les Indes orientales, l'auteur prend le parti d'étudier l'histoire de l'entreprise en se concentrant sur les comptoirs, tout particulièrement sur l'action et le vécu des agents de la Compagnie émigrés en terre étrangère.

La première Compagnie des Indes française est avant tout un projet politique dont le but est d'affirmer la présence de la France dans un espace maritime que la flotte nationale ne fréquente pas. C'est une administration de l'État fondée et dirigée à l'origine par Colbert dont le capital provient majoritairement du monde de la finance et non des marchands. Les débuts de la Compagnie se font dans la plus grande improvisation. En 1664, elle obtient le monopole de la navigation vers l'Asie mais les marins n'ont aucune connaissance des routes maritimes, n'ont pas les navires adéquats et n'ont pas d'escales déterminées. Madagascar est tout d'abord choisie pour constituer le point d'appui de la Compagnie dans l'océan Indien mais l'île, située à deux mois de navigation des côtes indiennes, ne convient pas et, après trois années d'errements, il devient nécessaire de s'installer sur le territoire indien où le comptoir de Pondichéry devient le centre principal de la Compagnie. Cette improvisation se retrouve dans le recrutement des agents qui ne reçoivent aucune instruction particulière avant de partir pour l'Asie. De plus, très rapidement, le fonctionnement des comptoirs souffre de la défaillance des circuits de communications entre la France et l'Inde. Les agents n'ont pas accès à l'information concernant les affaires d'Europe (guerres, changements politiques), ni même aux nouvelles sur leur propre activité comme les dates d'arrivées de navires. Ainsi vivent-ils de rumeurs dans un climat totalement anxiogène. De plus, ils n'ont aucune préparation à la vie quotidienne dans les comptoirs qui est d'une grande pénibilité en raison des conditions climatiques et qui provoque une forte mortalité. En conséquence, chez la plupart des employés domine une forte volonté de revenir en France.

Ainsi, dès sa création, la Compagnie n'a ni les agents, ni les outils nécessaires pour s'installer en Inde. Les usages locaux sont méconnus et les employés ne connaissent rien aux coutumes asiatiques. Ce sont des particuliers comme les marchands arméniens ou les courtiers indiens qui mettent leurs compétences au service de la Compagnie pour développer les échanges. Cependant, peu à peu les 
employés français se forment au commerce et aux coutumes de l'Inde mais sans aide ni contrôle de la métropole. Ainsi, la Compagnie est une structure fragilisée en raison de ce manque de coordination entre le siège parisien et les comptoirs indiens, ce qui ne lui permet pas d'affirmer sa présence face aux pouvoirs locaux. Aux Indes, il faut payer pour avoir l'autorisation de commercer, pour transporter des marchandises vers les ports, pour sortir un navire de la rade et, ensuite, il faut savoir maintenir de bonnes relations par des cadeaux et des gratifications. Tout ceci est difficile car, d'une part, la Compagnie a peu d'argent et, d'autre part, il est nécessaire de s'adapter à un contexte géopolitique très agité. Dans cette région du monde, la guerre est un état permanent. La première Compagnie des Indes subit ainsi une multitude de guerres locales entre principautés indiennes sans oublier les trois grands conflits européens de la période. De plus, la France doit vivre dans l'ombre de la voc, la puissance compagnie hollandaise qui fait tout pour entraver le commerce de ses concurrents, notamment celui des catholiques français. Pour résister, les Français se rapprochent des Portugais mais aucun des deux pays ne trouve dans l'autre les secours qu'il imagine. De son côté l'East India Company britannique a bien compris les faiblesses de la France aux Indes et manifeste de la bienveillance envers la compagnie française pour contrecarrer la puissance hollandaise, même si les deux pays se vouent une animosité profonde en Europe. Aux Indes, les Anglais sont les alliés officiels mais les ennemis officieux des Hollandais.

Alors que l'ambition de la Compagnie est de remplacer la voc sur les routes asiatiques, le bilan militaire des actions des escadres françaises en Asie est médiocre. Les moyens sont trop réduits pour pouvoir lancer des actions déterminantes et les prises ne sont que des événements anecdotiques qui, si elles sèment momentanément la panique, ne changent pas les rapports de force dans l'océan Indien. En outre, en raison des difficultés de ravitaillement, les escadres restent très peu de temps dans l'océan Indien. La Compagnie n'a aucune structure d'accueil, de radoub ou d'hivernage pour soutenir les opérations de vaisseaux de guerre. De plus, l'arrivée d'officiers du roi dans les comptoirs pour assurer leur sécurité provoque une animosité avec les agents de la Compagnie. Les militaires voient dans l'Inde un territoire à défendre, voire à soumettre, alors que les marchands y voient un territoire à exploiter et un lieu de vie. Finalement, la guerre de Succession d'Espagne met fin à cette première expérience française aux Indes. En Bretagne, Lorient, port de départ des navires partant vers l'Asie passe aux mains de la marine militaire et le commerce avec l'Inde disparaît.

La première compagnie des Indes françaises, qui n'a jamais fait un quelconque bénéfice, a été un échec financier. Ce résultat est dû à la méconnaissance totale du contexte politique et de la pratique du négoce indien par les agents de la Compagnie ainsi qu'à l'absence de véritables liens entre la métropole et ses comptoirs. Cependant, cette Compagnie laisse un héritage aux nouvelles entreprises qui voient le jour au $\mathrm{xVIII}^{\mathrm{e}}$ siècle. Elle a établi les routes par une meilleure appréhension de l'espace et du temps, organisé des comptoirs qui lui survivront et indiqué les marchandises à acheter pour les marchés qu'elle veut satisfaire. Pondichéry, même si son infrastructure portuaire est peu développée et ses abords peu navigables, restera le grand comptoir français aux Indes. Enfin, les agents envoyés dans les comptoirs ont donné naissance à une communauté française qui s'organise au sein de la société indienne. L'ouvrage de Marie Ménard-Jacob, dont l'originalité est de prendre le point de vue des acteurs des comptoirs qui sont l'élément essentiel de la construction de la Compagnie, est un apport de premier ordre à la connaissance de l'histoire des relations commerciales entre la France et l'espace asiatique à l'époque moderne. 